\title{
ERRATUM
}

\section{Y-chromosomal evidence of the cultural diffusion of agriculture in southeast Europe}

\author{
Vincenza Battaglia, Simona Fornarino, Nadia Al-Zahery, Anna Olivieri, Maria Pala, \\ Natalie M Myres, Roy J King, Siiri Rootsi, Damir Marjanovic, Dragan Primorac, \\ Rifat Hadziselimovic, Stojko Vidovic, Katia Drobnic, Naser Durmishi, Antonio Torroni, \\ A Silvana Santachiara-Benerecetti, Peter A Underhill and Ornella Semino
}

European Journal of Human Genetics (2009) 17, 853; doi:10.1038/ejhg.2009.21

Correction to: European Journal of Human Genetics (2009) 17, 820-830; doi:10.1038/ejhg.2008.249; published online 24 December 2008

Since the above publication, the authors have noticed a shift of the frequency values relative to $\mathrm{H} 1 \mathrm{a} 1$ and $\mathrm{I} 2 \mathrm{a} 1^{*}$ markers in Figure 2. The correct figure is reproduced below.
In addition, the authors would like to specify that the Macedonian sample of Cruciani et al. (2007) is from FYROM (Former Yugoslavia Republic of Macedonia).

The typesetters would like to apologise for this mistake.
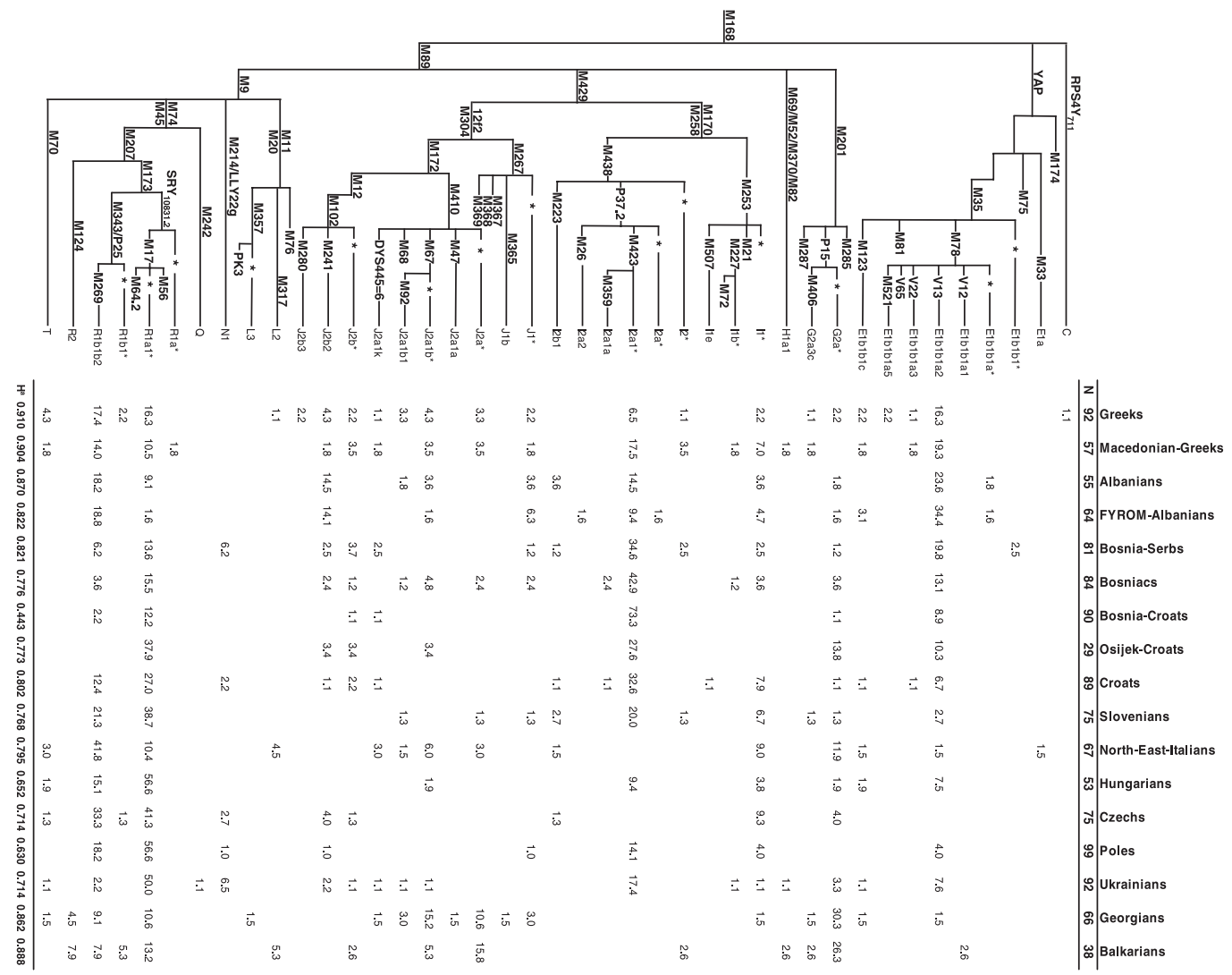

Figure 2 Phylogeny of $Y$-chromosome haplogroups and their frequencies (\%) in the examined populations. Nomenclature and haplogroup labelling according to the $\mathrm{Y}$ Chromosome Consortium (http://ycc.biosci.arizona.edu/) updated according to Karafet et al. *Paragroups: $\mathrm{Y}$

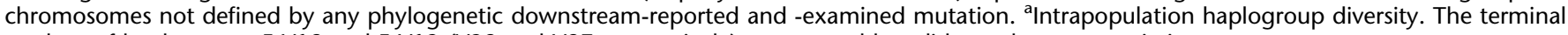
markers of haplogroups E-V12 and E-V13 (V32 and V27, respectively) were typed but did not show any variation. 